\title{
EFFECT OF MATERIAL ON STRESS TRANSMISSION TO THE SUPPORTING STRUCTURES IN KENNEDY CLASS I RESTORED BY TELESCOPIC-RETAINED REMOVABLE PARTIAL DENTURE. (STRAIN GAUGE STUDY)
}

\author{
Sherif Fayez Ahmed Bahgat* and Mahmoud El Moutassim Bellah El Homossany **
}

\begin{abstract}
Objectives: The aim of this in-vitro study was to compare the stresses transmitted to the abutments in mandibular Kennedy class I restored with telescopic-retained removable partial denture (RPD) made from two different materials; PolyEther Ether Ketone (PEEK) and Co-Cr alloy.

Materials and Methods: One mandibular model representing Kennedy class I, with second premolars as the last standing abutments, was fabricated using epoxy resin. Poly Vinyl Siloxane (PVS) impression material was used to simulate the mucosa and the periodontal ligament. The acrylic first and second premolar teeth bilaterally were prepared to receive primary telescopic copings. The latter and two removable partial denture (RPD) frameworks were fabricated out of PEEK and Co-Cr alloy. The 2 frameworks were then processed into fully finished RPDs using heat cured acrylic resin and acrylic teeth following the conventional techniques. Four strain gauges were installed in the epoxy resin model $1 \mathrm{~mm}$ mesial to the socket of the $1^{\text {st }}$ premolar and $1 \mathrm{~mm}$ distal to that of the $2^{\text {nd }}$ premolar, on the right and left sides respectively; channel 1,2,3 and 4. A load of $100 \mathrm{~N}$ was applied to the area of the first molar unilaterally on the right side and then bilaterally. The same procedure was repeated six times. Data on stresses were then collected, tabulated and statistically analyzed using one-way ANOVA and Tukey HSD Test $(\mathrm{P} \leq 0.05)$.
\end{abstract}

Results: In the unilateral loading condition, the highest compressive micro-strains were recorded at channel 3 for the Co-Cr alloy-group $(-40 \pm 3.16 \mu \mathrm{m} / \mathbf{m})$. While the least compressive micro-strains were recorded at channel 3 for the PEEK-group $(-10 \pm 3.16 \mu \mathrm{m} / \mathrm{m})$. The highest tensile micro-strains were recorded at channel 2 for the PEEK-group $(540 \pm 10 \mu \mathrm{m} / \mathrm{m})$. While the least tensile micro-strains were recorded at channel 4 for the PEEK-group $(15 \pm 4.47 \mu \mathrm{m} / \mathrm{m})$. In the bilateral loading condition, the highest tensile micro-strains were recorded at channel 2 for the PEEK-group $(355 \pm 11.83 \mu \mathbf{m} / \mathbf{m})$. While the least tensile micro-strains were recorded the same channel for the Co-Cr alloy-group $(50 \pm 3.16 \mu \mathrm{m} / \mathbf{m})$. The highest compressive micro-strains were recorded at channel 1 for the PEEK-group $(-170 \pm 11.4 \mu \mathrm{m} / \mathbf{m})$. While the least compressive microstrains were recorded at channel 3 for the Co-Cr alloy-group $(-95 \pm 8.94 \mu \mathbf{m} / \mathbf{m})$.

\footnotetext{
* Lecturer, Fixed Prosthodontics Department, Faculty of Dentistry, October University for Modern Sciences and Arts, Cairo, Egypt.

** Lecturer, Removable Prosthodontics Department, Faculty of Dentistry, Ain Shams University, Cairo, Egypt.
} 
Conclusions: The distal abutments always receive the highest stresses, regardless of the loading conditions and the materials from which the prosthesis was fabricated. Telescopic-retained RPD with metallic frameworks generate less strain to the supporting structures in Kennedy Class I compared to those with PEEK frameworks. The bilaterally applied force resulted in more favorable stress distribution pattern when compared to the unilateral one.

KEYWORDS: PEEK, strain-gauge, telescopic-retained RPD, Kennedy Class I, abutment.

\section{INTRODUCTION}

One of the most habitual partially edentulous clinical situations is the Kennedy class I, which represents bilateral posterior edentulous areas, with $20 \%$ and $50 \%$ incidence in the maxilla and the mandible, respectively. ${ }^{1}$ Extensive researches were conducted on the design and materials of different treatment options for such situations, among which; Tooth-tissue-supported removable partial denture (RPD), tooth-supported cantilever fixed partial denture (FPD), tooth-tissue-implant-supported RPD, tooth-implant-supported FPD, and implantsupported FPD.

Introduction of RPD comprises a risk feature for the remaining dentition periodontium. ${ }^{3}$ Therefore, many philosophies regarding the distal extension cases designs were suggested to prevent the resorption of the alveolar bone around the abutment teeth. ${ }^{4}$ This resorption results from torque of the clasped abutment teeth which represents a usual consequence of tissue ward movement of the RPD around the axis of rotation in Kennedy class I situations. ${ }^{5}$ Phoenix et al., 2008 stated that the philosophy of broad stress distribution decrease the occlusal load bearded by the residual ridge as there are no flexible or moving parts that distort the denture. ${ }^{6}$ Also, common clinical problems about RPD include lack of retention and stability, and unattractive look resulting from the display of metallic clasps..$^{7-12}$

Changing the Kennedy Class I situation to a more favorable tooth-tissue-implant-supported
RPD; Kennedy Class III configuration, via the insertion of single dental implant bilaterally in the molar area is becoming a popular treatment choice.$^{8,10,11,13-16}$ Placing the implants bilaterally, not only markedly improve the retention and stability of the prosthesis,,$^{7,810}$ but also, reduce the resorption of the alveolar ridges and the subsequent need of relining procedures..$^{17-19}$ Accordingly, this design improves the chewing ability, ${ }^{20}$ and resolves tissue ward movement problem of the RPD, which is transmitted as a shearing force, causing progressive resorption of residual ridges. ${ }^{21}$ This treatment option is considered more cost-effective when compared with implant-supported FPD and hence results in better patient satisfaction..$^{8,10,11}$ On the other hand, several studies, ${ }^{22-24}$ have reported several problems with tooth-tissue-implant-supported RPD, such as screw and healing caps loosening, and fracture of metal framework, and/or acrylic denture bases.

Another alternative treatment option represented to restore the Kennedy class I situations is the toothsupported cantilever FPD, ${ }^{25}$ to avoid the insertion of RPD. Most frequently, this type of fixed partial denture is used to replace the first molar; although occasionally it is used to replace the second molar to prevent super-eruption of opposing teeth. ${ }^{26}$ When the pontic is occlusally loaded, the adjacent abutment tends to act as a fulcrum, with a lifting tendency on the farthest retainer. The stress generated with this design is usually higher than in a conventional three-unit FPD, due to physical principles related to the size of the arm supported only in one end. ${ }^{27}$ To minimize the leverage effect, the pontic should be 
kept as small as possible, more nearly representing a premolar than a molar.

However, in spite of the progress in the aforementioned treatment options, tooth-tissuesupported RPD continues to be the selected treatment for many patients, especially those facing Kennedy class I situations. Relatively high cost and technical and biologic circumstances may contraindicate treatment with tooth-supported cantilever FPD, or implant-supported prosthesis whether tooth-tissueimplant-supported RPD, tooth-implant-supported FPD, and implant-supported FPD. ${ }^{28}$

Longevity of tooth-tissue-supported RPD requires protection and preservation of the remaining supporting structures. An optimized functional force distribution between the edentulous ridge and abutments is essential and particularly hard to reach when only a small number of abutment teeth remain..$^{29}$ The prosthodontist is left with the challenge of choice of a convenient retainer concerning the number, alignment, and periodontal condition of the remaining dentition, along with the esthetic needs, which affects the longevity of such restoration. ${ }^{30}$ Telescopic crowns were proven to be an efficient way of retaining tooth-tissue-supported RPD. They consist of a primary coping cemented to an abutment tooth and a precisely fitted secondary crown, as a part of the framework of the subsequent RPD. They have the benefit of transferring forces along the long axis of the abutment teeth, thus creating maximum areas of tension and minimum amount of compression in the periodontal membrane. ${ }^{31}$ These crowns are classified into two main categories: rigidly interlocked telescopic crowns and ones with built-in flexibility, based on surface interactions between the primary coping and secondary crown, which are responsible for retaining rigidly interlocked telescopic crowns when they are engaged. ${ }^{32}$ Accordingly, those with builtin resilience display no friction during insertion or removal; retention is achieved by using extra attachments or functional molded denture borders.

In the Marburg double-crown system, an attachment retained telescopic crown system has built-in resilience and hence retention is gained through an attachment. ${ }^{33}$ The apical one-third of the primary coping is made parallel to the secondary crown, which represents a part of the cast framework of the RPD and accurately fits onto the primary coping with no friction or wedging. Because of the stiffness of the framework, some authors, ${ }^{29,30}$ claimed that such design of RPD could be fabricated with neither major nor minor connectors.

According to the literature, it was proven that resilient attachments result in the least force on the abutments compared to rigid-precision attachments, ${ }^{34}$ which in turn result in more stress than do clasps. ${ }^{35}$ Some researchers reported that telescopic retainers create more strain and transmit more force occlusally to the terminal abutments than clasps do. ${ }^{36-38}$ However, in another research, telescopic-retained RPDs showed the most even transmission of forces occlusally compared to other design alternatives with precision attachments, clasps, or stress breakers. ${ }^{39}$

Telescopic-retained RPDs are regarded to be functionally equivalent with FPDs and are considered to be the most efficient alternate for missing teeth. This is considered true, as it has a favorable influence on stabilization of the remaining dentition and improvement of their periodontal health, ${ }^{40,41}$ and because of its retrievability, rendering it more accepted psychologically by some patients. ${ }^{42}$

Different materials have been introduced in the fabrication of distal extension RPD, in order to control excessive torque forces acting on the abutments and their related supporting structures. ${ }^{43}$

The use of high-performance biomaterial, PolyEther Ether ketone (PEEK-OPTIMA ${ }^{\mathrm{TM}}$ ), has increased in the field of dental medicine since the 1990s due to its superior properties, such as; its 
relatively high strength and flexibility (Young's modulus: 3-4 GPa), together with low density (1.32 $\mathrm{g} / \mathrm{cm}^{3}$ ), resistance to solvents, radiolucency and biocompatibility. ${ }^{44}$ Recently, JUVORA ${ }^{\mathrm{TM}}$ dental disc (United Kingdom) provided an unfilled PEEKOPTIMA $^{\mathrm{TM}}$, that is used in the field of dentistry for the prosthetic reconstructions, such as longterm implant borne, fixed and removable prosthetic frameworks, such as dentures, crowns, and bridges, by making it possible to meet the patients' desire for metal-free prostheses. Furthermore, due to its mechanical properties, which could be accustomed to certain requisites by adding, e.g., carbon fibers, PEEK better compensates mastication forces causing lower stress and a more even load distribution than other metallic materials. ${ }^{45}$

A variety of techniques were used in biomechanical investigations for both in-vitro and in-vivo studies, and yet no single technique met all of the requirements for illustration of the extensive physiological interactions involved. Complex analytical methods such as photogrammetry and finite element analyses are now possible because of the availability of high-capacity computer systems. ${ }^{46}$ However, strain gauge measurements were the adopted methodology in this study as they are the most accurate and widely used instruments to record surface stresses and to study the mechanics of prosthetic appliances in previous researches. ${ }^{47-49}$

In the literature, there are contradictory results about the force-transmission characteristics of telescopic RPDs, and little is known about their forcetransmission patterns related to different material types, rigidity (rigid or resilient), and a number of abutments supporting such telescopic dentures..$^{50}$ Hence, it seemed of value to investigate the stresses induced mesial and distal to the abutments during unilateral and bilateral loading conditions, using two different materials; Co-Cr alloy and PEEK for telescopic-retained RPD fabrication. The null hypothesis was that there would be no differences in the stresses transmitted to the supporting structures by the two different materials used.

\section{MATERIALS AND METHODS}

This in-vitro study was conducted on an educational acrylic model (Frasaco, Germany) with bilateral free end saddle, with the second premolars being the last standing teeth in the model.

\section{Model construction}

Silicone rubber base impression (Impregum Soft, 3M ${ }^{\mathrm{TM}}$ ESPE ${ }^{\mathrm{TM}}$, St. Paul, USA) was made for the acrylic model. The roots of acrylic first and second premolars for both sides were wrapped in $0.2 \mathrm{~mm}$ thickness tin foil and inserted in their corresponding positions in the silicone rubber base impression. The thickness of the foil was measured by dial gauge. Epoxy resin (Specifix, Stuers, Willich, Germany) was poured into the silicone rubber impression using a mechanical vibrator and was left to harden.

The acrylic teeth with tin foil spacer were then removed from the epoxy resin model. Their corresponding sockets were thoroughly cleaned from any remnants of tin foil and dried. The sockets and the root portions of the premolars were painted with rubber base adhesive (3M $\mathrm{M}^{\mathrm{TM}}$ ESPE ${ }^{\mathrm{TM}}$ VPS Tray

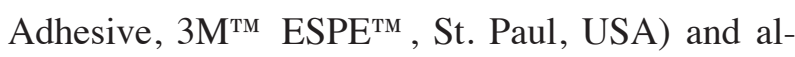
lowed to dry for 10 minutes. Light body Poly Vinyl Siloxane (PVS) impression material (Express ${ }^{\mathrm{TM}} 2$ Light Body Flow, 3M ${ }^{\mathrm{TM}}$ ESPE ${ }^{\mathrm{TM}}$, St. Paul, USA) was injected in the sockets of the premolars before repositioning of these teeth in their sockets in the epoxy resin model. This was done to simulate the periodontal ligaments (PDL) of the abutments.

A stone index (Type IV dental stone material, Syna-Rock, DFS-DIAMON, Germany), was made over the epoxy resin model covering the bilateral saddle areas. The outline of each denture was marked on the model. A round bur was used to make a uniform (2 $\mathrm{mm}$ thickness) reduction 
from the surface of epoxy resin under the denture base areas. Smoothening was performed for these areas, which were then painted with rubber base adhesive, and allowed to dry for 10 minutes. Even thickness of light body PVS impression material was applied and pressed into a layer of $2 \mathrm{~mm}$ thickness on the reduced outlined area using the stone index previously constructed. The epoxy resin model was removed from the stone index after setting of the PVS impression material. Abutment teeth (the first and second premolars bilaterally) were prepared, with a common path of insertion, to receive telescopic crowns with $2 \mathrm{~mm}$ occlusal

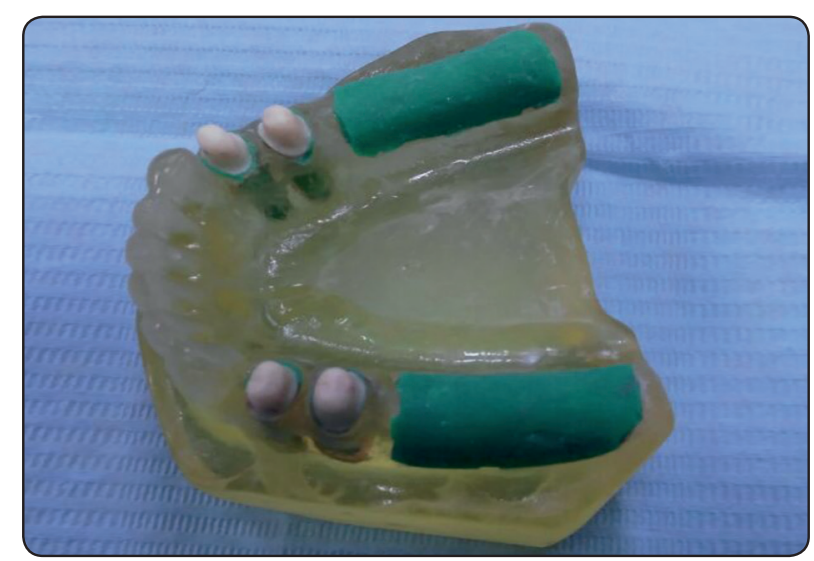

Fig (1): Complete model construction with prepared abutments.

reduction, facial reduction of $2 \mathrm{~mm}$, deep chamfer $1.5 \mathrm{~mm}$ wide, and occlusal angle of convergence of 6 degrees. ${ }^{33}$ (Figure 1)

The impression of the model with the prepared teeth was done with medium consistency rubber base material (Impregum Soft, 3M ${ }^{\mathrm{TM}} \mathrm{ESPE}^{\mathrm{TM}}$, St. Paul, USA) which was poured in stone (Type IV dental stone material, Syna-Rock, DFS-DIAMON, Germany) to produce the master model. Optical scan, D1000, 3Shape Dental System ${ }^{\mathrm{TM}}$ (3Shape A/S, Denmark) was made for the model. 3Shape Dental System $^{\text {TM }}$ (3Shape A/S, Denmark) software was used to design the primary copings with 6-degree convergence angle for the first and second pre- molars on both sides. Then the design of the secondary coping was made. An order was given to the milling machine to mill it in wax. After milling, the wax was cast into Co-Cr alloy, (Vitallium ${ }^{\circledR}$ Alloy, Vitallium System, USA). Another order was given to mill it in PEEK, (JUVORA ${ }^{\mathrm{TM}}$, United Kingdom). So, there were four primary copings made of metal and four others made of PEEK.

The epoxy resin model with the primary copings seated on their corresponding abutments was duplicated into a refractory model, on which the wax pattern for the RPD design was constructed. The wax pattern was sprued, invested, and cast into Vitallium, finished and polished. For the PEEK framework construction, design using 3shape software was performed and then milled using DATRON D5

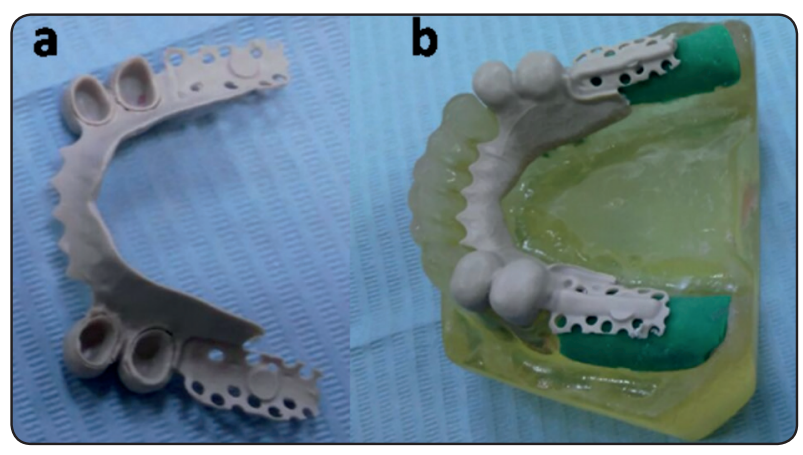

Fig (2): a) PEEK partial denture framework with the corresponding telescopic copings. b) Framework trial on the epoxy resin model.

5-axis dental milling machines (DATRON AG, Germany). The partial denture framework was seated and tried on the epoxy resin model. (Figure 2)

\section{Construction of the acrylic part of the denture base}

Setting up of acrylic teeth was carried out for both RPDs. The waxed up dentures were flasked, wax was eliminated, heat cured acrylic resin (DENTSPLY LIMITED, Weybridge, England) was 


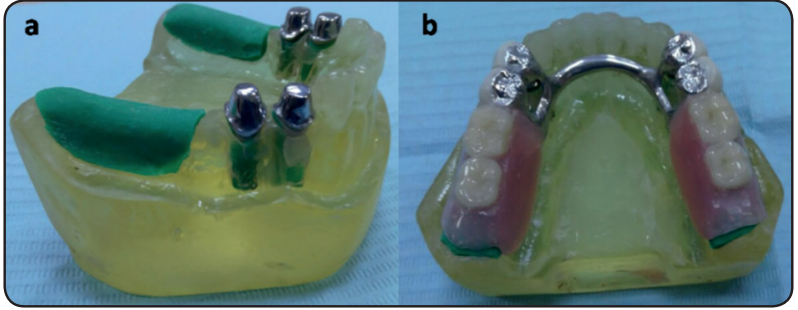

Fig (3): a. Metallic telescopic copings on their corresponding abutments. b. Finished RPD on the epoxy resin model

packed and cured, then finishing and polishing were carried out following the conventional techniques. (Figure 3)

\section{Installation of Strain Gauges}

The strain gauges used in this study were supplied with a fully encapsulated grid and attached wires. The strain gauges (kyowa strain gauges, Japan) used in this study had a length of $1 \mathrm{~mm}$, width $2.4 \mathrm{~mm}$ and nominal resistance $120 \mathrm{Ohm}$. Strain gauges were connected to lead wires $100 \mathrm{~cm}$ in length. All strain gauges were bonded in position to the epoxy resin model with delicate layer of cyanoacrylate adhesive (CC-33A, EP-34B; Kyowa Electronic Instruments Co., Ltd.). The wires of the strain gauges were embedded in grooves created in the base of the model and fixed in position using adhesive .The loading device universal testing machine (LLOYD Universal Testing Machine, U.K.), was used for applying vertical static loads ranging between $0-100$ Newton on the loading points. The loading device consists of a base, frame, model fixture and the loading point.

The four strain gauges were installed in vertical grooves in the epoxy resin model $1 \mathrm{~mm}$ mesial to the socket of the $1 \mathrm{st}$ premolar and $1 \mathrm{~mm}$ distal to the socket of the 2nd premolar, on the right and left sides respectively; channel 1,2,3 and 4. (Figure 4) The gauges were oriented vertically and attached to their planned positions by a cyanoacrylate adhesive.

\section{Strain Gauge analysis}

\section{Load application and recording micro strains:}

For each of the tested material, the telescopic

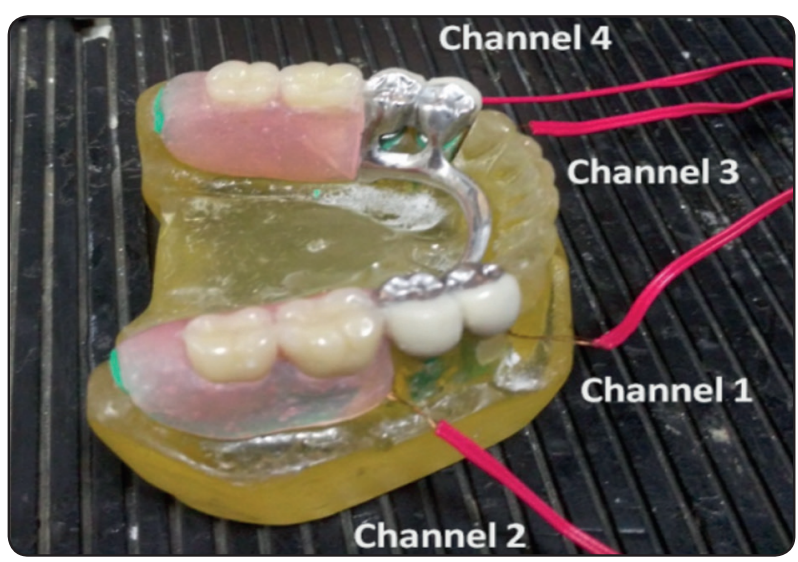

Fig (4): Micro-strain gauges attached to the model with the channels specification.

primary copings were first cemented on their corresponding abutments using temporary cement (Cavex Temporary Cement, Cavex, Holland BV) before seating of their corresponding telescopicretained RPD on the epoxy resin model which was then placed on the lower metal plate of the universal testing machine. Four strain-meters were used to record the micro-strains transmitted to each strain gauge. The lead wire from each active strain gauge was connected to the strain-meter. All the connected gauges were tested before load application to ensure that they are working. T-shaped load applicator bar of the testing machine was applied to the 1st molar teeth of the denture. The load was applied unilaterally then bilaterally. The applied static load started from zero up to $100 \mathrm{~N}$. Even contacts between the bar and the artificial teeth on both sides for bilateral load application were achieved by spot grinding using articulating paper.

The micro-strains of the four strain gauges were recorded to measure the strains developed at the mesial wall of the socket of the 1st premolar and the distal one of the 2nd premolar, bilaterally. The micro strain readings were transferred to micro strain units through the four channel strain-meters. Enough time was elapsed (about 15 minutes) between every two successive measures to allow complete rebound of the resilient structure. (Figure 5) 


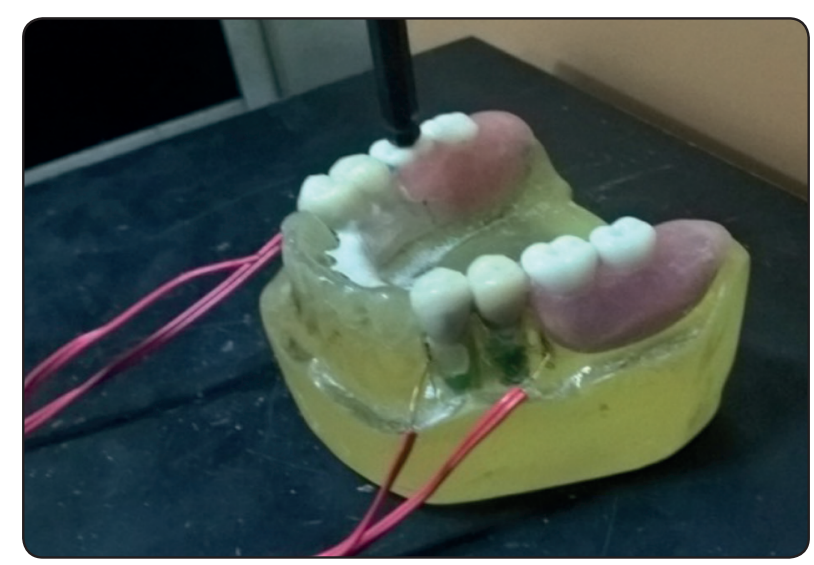

Fig (5): Unilateral load application on the right side for microstrain measurement for the PEEK telescopic-retained RPD.

\section{Statistical Analysis}

Statistical analysis was performed with SPSS (v 20, IBM Corporation, Armonk, NY, USA) for Windows. Data for micro-strain gauge analysis are presented as mean and standard deviation (SD) values. Data was explored for normality using D'Agostino-Pearson test. Micro-strains $(\mu \mathrm{m} / \mathrm{m})$ showed normal distribution for the unilateral and bilateral loading conditions. One Way ANOVA was used to compare between the interactions between variables followed by Tukey HSD Test to study the effect of different materials and loading conditions on the mean micro-strains $(\boldsymbol{\mu} \mathbf{m} / \mathbf{m})$ within each group; separately. The significance level was set at $\mathrm{P} \leq 0.05$.

\section{RESULTS}

Means and standard deviations (SD) of microstrains $(\mu \mathrm{m} / \mathrm{m})$ around abutment teeth for different materials and loading conditions are presented in table (1), where (-ve = compressive micro-strain and $+\mathrm{ve}=$ tensile micro-strain) .

\section{Unilateral loading:}

In the unilateral loading condition, micro-strains recorded for Co-Cr alloy and PEEK-groups were tensile (positive) in nature in the right side (the load acting side) at both channel 1 and channel 2 as well as the channel 4 in the PEEK-group. While at channel 3, it was compressive for $\mathrm{Co}-\mathrm{Cr}$ alloy and PEEK-groups as well as the channel 4 for the Co$\mathrm{Cr}$ alloy-group. The highest tensile micro-strain was recorded at channel 2 for the PEEK-group $(540 \pm 10$ $\mu \mathrm{m} / \mathrm{m})$. While, the least tensile micro-strain was recorded at channel 4 for the PEEK-group $(15 \pm 4.47$ $\mu \mathrm{m} / \mathrm{m})$.

The highest compressive micro-strain was recorded at channel 3 for $\mathrm{Co}-\mathrm{Cr}$ alloy-group $(-40 \pm 3.16 \mu \mathbf{m} / \mathbf{m})$. While the least compressive micro-strain was recorded at channel 3 for the PEEK-group $(-10 \pm 3.16 \mu \mathrm{m} / \mathrm{m})$. (Table 2, figure 6)

\section{Effect of strain gauge location: (Table 2, figure 6)}

In the Co-Cr alloy-group, channel 1 recorded the statistically significant highest mean microstrain $(155 \pm 8.37 \mu \mathbf{m} / \mathbf{m})$ followed by channel 2

TABLE (1) Means and standard deviations of micro-strains $(\mu \mathrm{m} / \mathrm{m})$ of different materials and loading conditions

\begin{tabular}{|c|c|c|c|c|c|c|c|c|}
\hline & \multicolumn{4}{|c|}{ Unilateral } & \multicolumn{4}{c|}{ Bilateral } \\
\cline { 2 - 9 } & Channel 1 & Channel 2 & Channel 3 & Channel 4 & Channel 1 & Channel 2 & Channel 3 & Channel 4 \\
\hline Co-Cr alloy & $155 \pm 8.37$ & $125 \pm 7.75$ & $-40 \pm 3.16$ & $-30 \pm 9.49$ & $-110 \pm 10$ & $50 \pm 3.16$ & $-95 \pm 8.94$ & $65 \pm 6.32$ \\
\hline PEEK & $260 \pm 3.65$ & $540 \pm 10$ & $-10 \pm 3.16$ & $15 \pm 4.47$ & $-170 \pm 11.4$ & $355 \pm 11.83$ & $-155 \pm 13.04$ & $340 \pm 10.49$ \\
\hline
\end{tabular}


TABLE (2) Means and standard deviations of micro-strains $(\mu \mathrm{m} / \mathrm{m})$ of the two different materials in unilateral loading condition

\begin{tabular}{|c|c|c|c|c|c|}
\hline & \multicolumn{4}{|c|}{ Unilateral } & \multirow{2}{*}{ P-value } \\
\cline { 2 - 5 } & Channel 1 & Channel 2 & Channel 3 & Channel 4 & \\
\hline Co-Cr alloy & $155 \pm 8.37^{\mathrm{a}}$ & $125 \pm 7.75^{\mathrm{b}}$ & $-40 \pm 3.16^{\mathrm{ac}}$ & $-30 \pm 9.49^{\mathrm{ac}}$ & $<0.0001^{*}$ \\
\hline PEEK & $260 \pm 3.65^{\mathrm{abc}}$ & $540 \pm 10^{\mathrm{abc}}$ & $-10 \pm 3.16^{\mathrm{abd}}$ & $15 \pm 4.47^{\mathrm{abd}}$ & \\
\hline $\boldsymbol{P}$ P-value & $<0.0001^{*}$ & $<0.0001^{*}$ & $<0.0001^{*}$ & $<0.0001^{*}$ & \\
\hline
\end{tabular}

*; significant between the two different materials ( $p<0.05)$, different letters indicating significance among the channels $(p<0.05)$

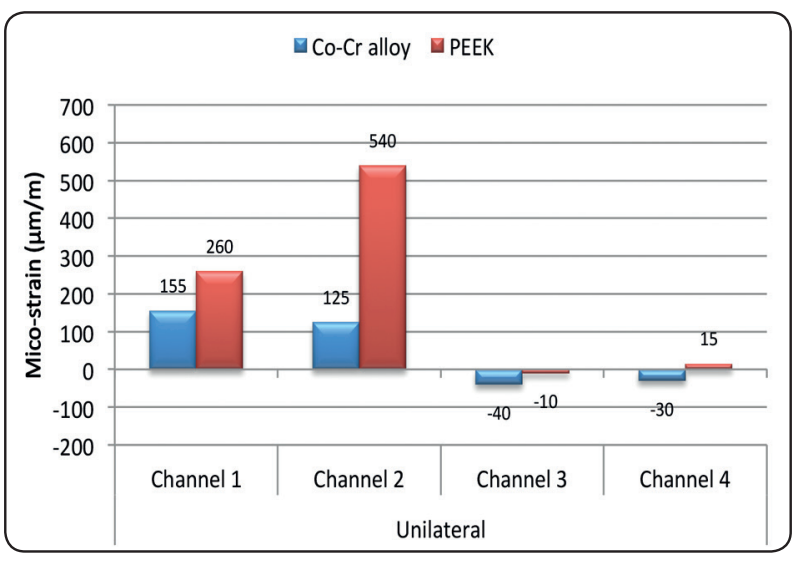

Fig (6): Column chart showing the mean micro-strains $(\mu \mathrm{m} / \mathrm{m})$ of the two different materials in the unilateral loading condition.

$(125 \pm 7.75 \mu \mathbf{m} / \mathbf{m})$, followed by channel $3(-40 \pm 3.16$ $\boldsymbol{\mu} \mathbf{m} / \mathbf{m})$, followed by channel $4(-30 \pm 9.49 \mu \mathbf{m} / \mathbf{m})$ which recorded the lowest statistically significant mean micro-strain $(p<0.001)$.

In the PEEK-group, channel 2 recorded the statistically significant highest mean micro-strain $(540 \pm 10 \mu \mathrm{m} / \mathbf{m})$ followed by channel $1(260 \pm 3.65$ $\boldsymbol{\mu} \mathbf{m} / \mathbf{m})$, followed by channel $4(15 \pm 4.47 \mu \mathbf{m} / \mathbf{m})$, followed by channel $3(-10 \pm 3.16 \mu \mathrm{m} / \mathbf{m})$ which recorded the lowest statistically significant mean micro-strain $(p<0.001)$.

\section{Effect of prosthesis material: (Table 2, figure 6)}

At channel 1 and 2, PEEK-group showed statistically significant higher mean micro-strains compared to Co-Cr alloy-group $(p<0.001)$. While at channel 3 and 4, Co-Cr alloy-group showed statistically significant higher mean micro-strains compared to PEEK-group $(p<0.001)$.

\section{Bilateral loading:}

In the bilateral loading condition, micro-strains recorded for $\mathrm{Co}-\mathrm{Cr}$ alloy and PEEK-groups were compressive (negative) in nature in mesial strain gauges, at both the right and left sides (channel 1 and 3). While in distal strain gauges, it was compressive in nature, at both the right and left sides (channel 2 and 4) for Co-Cr alloy and PEEKgroups. The highest compressive micro-strain was recorded at channel 1 for PEEK-group $(-170 \pm 11.4$ $\boldsymbol{\mu} \mathbf{m} / \mathbf{m})$. While the least compressive micro-strain was recorded at channel 3 for the $\mathrm{Co}-\mathrm{Cr}$ alloy-group $(-95 \pm 8.94 \mu \mathrm{m} / \mathbf{m})$.

The highest tensile micro-strain was recorded at channel 2 for PEEK-group $(355 \pm 11.83 \mu \mathbf{m} / \mathbf{m})$. While the least tensile micro-strain was recorded on the same channel for the $\mathrm{Co}-\mathrm{Cr}$ alloy-group $(50 \pm 3.16 \mu \mathrm{m} / \mathbf{m})$. (Table 3, figure 7) 
TABLE (3) Means and standard deviations of micro-strains $(\mu \mathrm{m} / \mathrm{m})$ of the two different materials in the bilateral loading condition

\begin{tabular}{|c|c|c|c|c|c|}
\hline & \multicolumn{4}{|c|}{ Bilateral } & \multirow{2}{*}{$P$-value } \\
\hline & Channel 1 & Channel 2 & Channel 3 & Channel 4 & \\
\hline Co-Cr alloy & $-110 \pm 10^{\mathrm{a}}$ & $50 \pm 3.16^{b}$ & $-95 \pm 8.94^{\mathrm{a}}$ & $65 \pm 6.32^{\mathrm{b}}$ & \multirow{2}{*}{$<0.0001 *$} \\
\hline PEEK & $-170 \pm 11.4^{\mathrm{c}}$ & $355 \pm 11.83^{\mathrm{ab}}$ & $-155 \pm 13.04^{c}$ & $340 \pm 10.49^{\mathrm{ab}}$ & \\
\hline$P$-value & $<0.0001 *$ & $<0.0001 *$ & $<0.0001 *$ & $<0.0001 *$ & \\
\hline
\end{tabular}

*; significant between the two different materials $(p<0.05)$, different letters indicating significance among the channels $(p<0.05)$

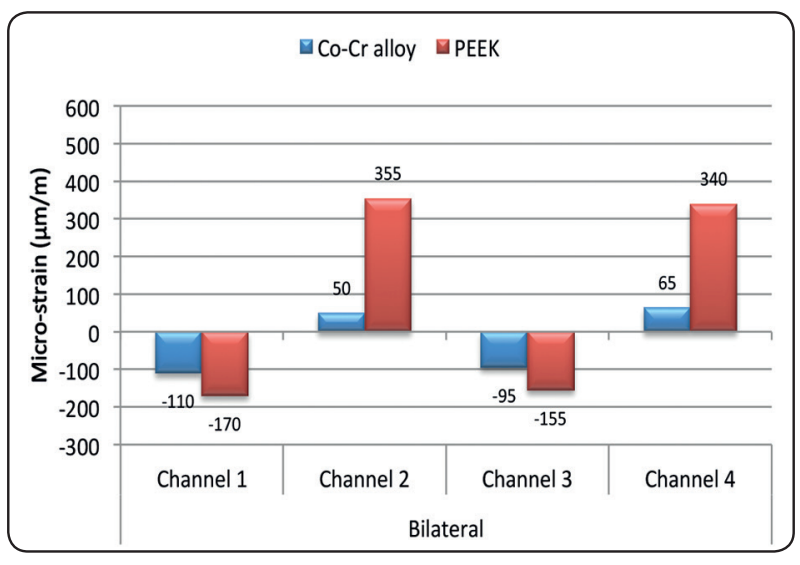

Fig (7): Column chart showing the mean micro-strains $(\mu \mathrm{m} / \mathrm{m})$ of the two different materials in the bilateral loading condition.

Effect of strain gauge location: (Table 3, figure 7)

In the Co-Cr alloy-group, channel 1 recorded the statistically significant highest mean micro-strain $(-110 \pm 10 \mu \mathbf{m} / \mathbf{m})$ followed by channel $3(-95 \pm 8.94$ $\boldsymbol{\mu} \mathbf{m} / \mathbf{m})$, followed by channel $4(65 \pm 6.32 \mu \mathbf{m} / \mathbf{m})$, followed by channel $2(50 \pm 3.16 \mu \mathrm{m} / \mathbf{m})$ which showed the lowest statistically significant mean micro-strain $(p<0.001)$.

In the PEEK-group, channel 2 recorded the statistically significant highest mean micro-strain $(355 \pm 11.83 \mu \mathbf{m} / \mathbf{m})$ followed by channel 4 (340 \pm $10.49 \mu \mathbf{m} / \mathbf{m})$, followed by channel $1(-170 \pm 11.4$ $\boldsymbol{\mu} \mathbf{m} / \mathbf{m})$ followed by channel $3(-155 \pm 13.04 \mu \mathbf{m} / \mathbf{m})$ which showed the lowest statistically significant mean micro-strain $(p<0.001)$.

\section{Effect of prosthesis material: (Table 3, figure 7)}

At channel 1,2, 3 and 4, PEEK-group recorded statistically significant higher mean micro-strains compared to Co-Cr alloy-group $(p<0.001)$.

\section{DISCUSSION}

Telescopic crowns are universally recognized and mostly used as retentive elements for restoration of the partially edentulous dentition, using RPD. This is because of the high degree of intraoral comfort and the good long-term practicability provided by such attachment system, as assured in the literature. ${ }^{50}$ Also it is well documented that the use of this attachment system to retain RPD is more efficient than the usual clasps because of their capability of occlusal loading transmission to the abutment's long axis and to provide guidance, support and stability. ${ }^{51-53}$ Unfortunately, the frictional wear during the functional period represents a common problem of the double crown retention concept. Also; data about the retentive forces of telescopic crowns are mostly gathered from laboratory researches, with limited clinical ones..$^{50}$

However, an in-vitro protocol was conducted to perform this experiment as in-vitro studies have been used more widely than in-vivo ones in stress analysis of oral structures, due to the fact that they are 
more easily controlled, and can furnish more precise results particularly with comparative researches. On the other hand, un-standardized reproducibility of the in-vivo test with the same supporting teeth and mucosa always represents a predicament, because of the periodontal tissues' histological structures and bone consistency variability among patients. In addition, the length and width of the roots are different. ${ }^{54}$

The model used for this study was fabricated to simulate as much as possible the natural condition. PVS impression material was used to simulate the visco-elastic behavior of the mucous membrane covering the residual ridges under the denture bearing area. It was used for this purpose because it has the lowest values of dimensional changes and permanent deformation, and requires less time to recover the visco-elastic deformation among all rubber impression materials. ${ }^{48}$ Also in order to provide a stable non-movable model surface, an adhesive was used for bonding the silicone layer that simulated the oral mucosa to the underlying epoxy resin model..$^{55}$

Although the mechanical behavior of the PVS impression material, used to simulate the PDL invitro, is different from what is expected for the PDL in-vivo, the load applied to the prosthesis in this study was not load to failure so the influence of the supporting structures, including the PDL was considered to be minor. ${ }^{2}$

In the current research, the strain gauge analysis was the adopted method to evaluate strain around abutment teeth as it provides quantitative analysis of the strain around abutment teeth supporting a distal extension, as being one of the frequent methods used for strain analysis in dentistry. ${ }^{56}$ This is due to their miniature dimension, linearity, and minimal interference during testing procedures.$^{57}$ It is also considered to be a stable and an accurate system. It assesses strains induced into a loaded structure by changing the resistance of an electric wire, insulated by a packing material so as to be protected from humidity in order to obtain reliable recordings, ${ }^{58,59}$ into strain measurement. ${ }^{48}$

Moreover the use of in-vivo strain gauges comprises many shortcomings including, short circuits could not be prevented due to the difficulty in isolation of the gauges from saliva and blood, and the unavoidable patient movement resulting in motion of the wire that usually produces inaccurate results. Consequently, in-vitro strain gauge researches remain as valuable guides to the clinicians awaiting the feasibility to conduct such studies on large scale in order to have statistically concrete conclusions. ${ }^{54}$

In an attempt to prevent the incidence of inaccurate incremental strains, the sites of mounting of the strain gauges were prepared and made flat to avoid their mounting on curved surfaces.$^{60}$ In order to standardize the level of sensitivity to the applied load; all the strain gauges used in this research exhibited the same dimensions, resistance and gauge factor. When the test was executed, they were also properly located, adhered in their planned positions to standardize their location, and connected in an attempt to eliminate incorrect recordings resulting due to high sensitivity of strain gauges to any variation occurring during load applications..$^{58}$

The present study was concerned with one treatment modality used for rehabilitation of mandibular Kennedy class I cases, using 2 different materials, Co-Cr alloy, and PEEK and their effect on the strain induced in the supporting structures for these telescopic-retained RPD. PEEK-OPTIMA ${ }^{\mathrm{TM}}$ was the selected material to be compared with the traditional Co-Cr alloy material in this study as it is the only non-metallic material that has been approved by the FDA, CE and ANVISA, for longterm implant-supported, fixed and removable prosthetic frameworks, such as RPDs, crowns and FPDs. ${ }^{61}$ Mandibular model was used instead of maxillary one as most of the clinical problems 
were reported in mandibular cases because of the inadequate denture bearing area and the nature of the underlying mucosa essential for its support. ${ }^{62}$

The design was the same for the two groups except that the major connector for the PEEK was lingual plate as recommended by the manufacturer as to increase the rigidity needed for its fabrication and thus limiting the possible difference in strains recorded to the type of material used.$^{48}$ Concerning the cementation of the telescopic retainers, the thickness of the cement layer used was kept minimum in order to avoid the effect of thick cement layer on the obtained data. ${ }^{48}$

Unilateral and bilateral loads were applied. The load application sites for bilateral loading were adjusted using articulating paper to provide even and simultaneous loading on both sides of the partial denture. Loading was performed on the 1st molar area, where most of the masticatory activity usually occurs. ${ }^{43}$ The maximum load applied was about $100 \mathrm{~N}$ in order to correspond to the average chewing force required for most food types. Enough time (15 minutes) was given to the strain gauges to be in zero balance and to allow complete rebound of the resilient structures before recording the next reading. ${ }^{63}$

Findings of the current study revealed that the highest strain was always observed distal to the abutments, especially for the PEEK telescopicretained RPD ( $540 \mu \mathbf{m} / \mathbf{m})$, which makes sense, if we took into consideration the movement of the distal portion of the free-end saddles caused by the teeth and dentures vertical displacement. The findings also proved that $\mathrm{Co}-\mathrm{Cr}$ alloy telescopicretained RPD generated less strain in the residual alveolar ridges and abutments. The difference was statistically significant $(P<0.0001)$.

According to the literature, ${ }^{37,64,65}$ the more rigid the connection for the retainer the less would be the denture mobility and vice versa. These observations coincided with our study in which PEEK telescopic- retained RPD resulted in statistically significant higher strain in most of the channels when compared to $\mathrm{Co}-\mathrm{Cr}$ alloy one. This could be attributed to the much higher Young's modulus of Co-Cr alloy $(220-230 \mathrm{GPa})^{66}$ compared to that of the PEEK $(3-4 \mathrm{GPa}){ }^{44}$

Decreasing the RPD mobility is considered of great value regarding the maintenance of the residual ridge for free-end saddle RPD ${ }^{67}$ Also a more stable occlusion during occlusal functioning would contribute to the maintenance of the temporomandibular joint in the normal relationship and decrease the possibility of patient's discomfort. ${ }^{68}$ Furthermore, the more the rigidity of the RPD retainer the less would be abutment mobility ${ }^{69,70}$

Furthermore, the findings of our study revealed that, in most of the situations, the terminal abutment of attachment involved a greater risk than the mesial one, which was in accordance with Bergman et al., $1982,{ }^{71}$ who reported that at least two abutment teeth should be splinted when attachment prostheses are to be used for better stress pattern.

Another finding in the current research was that, in the unilateral loading condition, the strain generated in the contra-lateral side of load application (left side), was greater concerning the Co-Cr alloy-group ( $40 \mu \mathbf{m} / \mathbf{m}$ ) compared to that of the PEEK one $(10 \mu \mathbf{m} / \mathbf{m})$, which was statistically significant $(P<0.0001)$. This might be attributed to the rigidity of the $\mathrm{Co}-\mathrm{Cr}$ alloy major connector and the use of rigid telescopic retainers. This was in agreement with Feingold et al., 1988, ${ }^{72}$ who stated that the use of the rigid-connection retainer and cross-arch stabilization was effective in the reduction of the denture base movement, which was achieved through the use of metallic telescopic that showed the least displacement among other designs.

This was also in coincidence with Saito et al., $1998,^{73}$ who proved that the base movement of a rigid attachment was less than that of a resilient one, as the displacement of the denture base decreased 
with the increase in the rigidity of the connection of the retainer to abutments.

On the other hand, our results did not agree with Sahin et al., 2012, ${ }^{33}$ who found that the rigid-retainer designs resulted in greater stress on the abutments than did the resilient ones. Also, they were not in accordance with Ogata et al., 1992, ${ }^{74}$ and Ogata and Watanabe, $1993,{ }^{75}$ who proved that there were no remarkable differences, regarding torque around the vertical axis of an abutment, between the distalextension RPDs with different rigidity. This may be attributed to the differences in study design between the current research and theirs which was in-vivo one resulting in the presence of many specific factors concerning each patient rather than the design of the dentures, such as; alveolar mucosa properties, the alveolar ridge shape, or the chewing pattern, would affect the torque around the vertical axis. ${ }^{75}$

Comparing the unilateral to the bilateral loading conditions, it seemed that the pattern of stress distribution was better in the latter, regardless of the material from which the prosthesis was constructed. This was in accordance with Shahmiri et al., $2013,{ }^{2}$ who suggested the use of bilateral balanced occlusion for distal extension RPD to evenly distribute forces across the prosthesis; though, such an occlusal scheme could not simply be achieved in cases where the opposing arch is fully dentulous. ${ }^{76}$

Finally, a limitation of this study was that it was carried out in-vitro, without taking into consideration the effect of individual patient variation regarding the supporting structures for the fabricated prostheses. Thus, future clinical trials should be carried out as such in-vitro researches do not eradicate the requirement for clinical ones. It is worth mentioning that the null hypothesis which suggested that there would be no differences in the stresses transmitted to the supporting structures by the two different materials used was rejected, as the results of the current study showed a significance difference between them.

\section{CONCLUSIONS}

Within the limitation of this study and under the test conditions, the following could be concluded:

1. The distal abutments always exhibit the highest strain, regardless of the loading conditions and the materials from which the prosthesis was fabricated.

2. Co-Cr alloy telescopic-retained RPD could still be considered a better choice for rehabilitation of the Kennedy Class I partial edentulous situations compared to PEEK one, as the former generates less stresses to the denture supporting structures.

3. The pattern of stress distribution is better in bilateral loading condition, regardless of the materials from which the prosthesis was constructed.

\section{DISCLOSURE}

The authors report no conflicts of interest in this work.

\section{REFERENCES}

1. Stratton, R.S., Wiebelt, F.J. An atlas of removable partial denture design. Chicago: Quintessence, 1988, pp. 9b, 135, 175, 197, 207, 243, 273, 313.

2. Shahmiri R, Aarts JM, Bennani V, Das R, Swain MV. Strain Distribution in a Kennedy Class I Implant Assisted Removable Partial Denture under Various Loading Conditions. Int J Dent, 2013; 22:550-555.

3. Abd El.Khalik MM, El Mekawy NH, El-Kasaby SS. Mandibular Kennedy class I partial denture management by broad stress distribution philosophy (radiographic assessment). J Indian Prosthodont Soc, 2016; 16:282-287.

4. Gupta G, Goyal V, Kadian A. Different runways for edentulous areas. Int J Enhanced Res Med Dent Care, 2014; $1: 58$.

5. Chou TM, Eick JD, Moore DJ, Tira DE. Stereophotogrammetric analysis of abutment tooth movement in distalextension removable partial dentures with intracoronal attachments and clasps. J Prosthet Dent, 1991; 66:343349. 
6. Phoenix RD, Cagna DR, Defreest CH. Stewart's Clinical Removable Partial Prosthodontics. 4th ed. Chicago: Quintessence Publishing Co.; 2008. 1822.

7. Gonçalves TM, Campos CH, Garcia RC. Implant retention and support for distal extension partial removable dental prostheses: Satisfaction outcomes. J Prosthet Dent, 2014; 112:334339.

8. Zancopé K, Abrão GM, Karam FK, Neves FD. Placement of a distal implant to convert a mandibular removable Kennedy class I to an implantsupported partial removable Class III dental prosthesis: A systematic review. J Prosthet Dent, 2015; 113:528533.

9. Bortolini S, Natali A, Franchi M, Coggiola A, Consolo U. Implantretained removable partial dentures: An 8year retrospective study. J Prosthodont, 2011; 20:168172.

10. Ohkubo C, Kobayashi M, Suzuki Y, Hosoi T. Effect of implant support on distalextension removable partial dentures: In-vivo assessment. Int J Oral Maxillofac Implants, 2008; 23:10951101.

11. Mitrani R, Brudvik JS, Phillips KM. Posterior implants for distal extension removable prostheses: A retrospective study. Int J Periodontics Restorative Dent, 2003; 23:353359.

12. Kono K, Kurihara D, Suzuki Y, Ohkubo C. Pressure distribution of implantsupported removable partial dentures with stressbreaking attachments. J Prosthodont Res, 2014; 58:115120

13. Bural C, Buzbas B, Ozatik S, Bayraktar G, Emes Y. Distal extension mandibular removable partial denture with implant support. Eur J Dent, 2016; 10:566-570.

14. Keltjens HM, Kayser AF, Hertel R, Battistuzzi PG. Distal extension removable partial dentures supported by implants and residual teeth: Considerations and case reports. Int J Oral Maxillofac Implants, 1993; 8:208213.

15. Elsyad MA, Habib AA. Implantsupported versus implantretained distal extension mandibular partial overdentures and residual ridge resorption: A 5year retrospective radiographic study in men. Int J Prosthodont, 2011; 24:306313.

16. Mijiritsky E, Karas S. Removable partial denture design involving teeth and implants as an alternative to unsuccessful fixed implant therapy: A case report. Implant Dent, 2004; 13:218222.

17. Verri FR, Pellizzer EP, Rocha EP, Pereira JA. Influence of length and diameter of implants associated with distal extension removable partial dentures. Implant Dent, 2007; 16:270280.

18. Griffin TJ, Cheung WS. The use of short, wide implants in posterior areas with reduced bone height: A retrospective investigation. J Prosthet Dent, 2004; 92:139144.

19. De Freitas RF, de Carvalho Dias K, da Fonte Porto Carreiro A, Barbosa GA, Ferreira MA. Mandibular implantsupported removable partial denture with distal extension: A systematic review. J Oral Rehabil, 2012; 39:791798.

20. Mijiritsky E., Ormianer Z., Klinger A., Mardinger O. Use of dental implants to improve unfavorable removable partial denture design. Compend Contin Educ Dent, 2005; 26(10):744-746.

21. Witter D. J., De Haan A. F., Kayser A. F., Van Rossum G. M. A 6-year follow-up study of oral function in shortened dental arches-part II: craniomandibular dysfunction and oral comfort. J Oral Rehabil, 1994; 21(4);353-366.

22. Grossmann Y., Nissan J., Levin L. Clinical effectiveness of implant-supported removable partial dentures - a review of the literature and retrospective case evaluation. J. Oral Maxillofac. Surg., 2009; 67(9):1941-1946.

23. Payne A., Kuzmanovic D. V., De Silva K. R., Van Staden I. P. Mandibular removable partial dentures supported by implants: one-year prosthodontic outcomes. J. Dent. Res.2006; 85:2570.

24. Kaufmann R., Friedli M., Hug S., Mericske-Stern R. Removable dentures with implant support in strategic positions followed for up to 8 years. Int J Prosthodont, 2009; 22(3):233-242.

25. Ewing JE. Re-evaluation of the cantilever principle. J Prosthet Dent, 1975; 7:78-92.

26. Himmel R, Pilo R, Assif D, Aviv I. The cantilever fixed partial denture: a literature review. J Prosthet Dent, 1992; 67:484-487.

27. Correia A., Fernandes J., Campos J., Vaz M., Ramos N. Stress analysis of cantilever-fixed partial denture connector design using the finite element method. Rev. odonto ciênc, 2009; 24(4):420-425.

28. Curtis D. A., Curtis T. A., Wagnild G. W. Finzen F. C. Incidence of various classes of removable partial dentures. J Prosthet Dent., 1992; 67(5): 664-667.

29. Wenz HJ, Lehmann KM. A telescopic crown concept for the restoration of the partially edentulous arch: the 
Marburg double crown system. Int J Prosthodont, 1998; 11:541-550.

30. Wenz HJ, Hertrampf K, Lehmann KM. Clinical longevity of removable partial dentures retained by telescopic crowns: outcome of the double crown with clearance fit. Int J Prosthodont, 2001; 14:207-213.

31. Isaacson GO. Telescope crown retainers for removable partial dentures. J Prosthet Dent, 1969; 22:436-448.

32. Langer A. Telescope retainers and their clinical application. J Prosthet Dent, 1980; 44:516-522

33. Sahin V., Akaltan F., Parnas L. Effects of the type and rigidity of the retainer and the number of abutting teeth on stress distribution of telescopic-retained removable partial dentures. Journal of Dental Sciences, 2012; 7:7-13.

34. Kratochvil FJ, Thompson WD, Caputo AA. Photoelastic analysis of stress patterns on teeth and bone with attachment retainers for removable partial dentures. J Prosthet Dent, 1981; 46:21-28.

35. Chou TM, Caputo AA, Moore DJ, Xiao B. Photoelastic analysis and comparison of force-transmission characteristics of intracoronal attachments with clasp distal-extension removable partial dentures. J Prosthet Dent, 1989; 62:313319.

36. Saito M, Miura Y, Notani K, Kawasaki T. Stress distribution of abutments and base displacement with precision attachment and telescopic crown-retained removable partial dentures. J Oral Rehabil, 2003; 30:482-487.

37. Igarashi Y., Ogata A., Kuroiwa A., Wang C. H. Stress distribution and abutment tooth mobility of distal-extension removable partial dentures with different retainers: an invivo study. J Oral Rehabil, 1999; 26; 111-116.

38. Ogata K, Okunishi M, Miyake T. Longitudinal studies on forces transmitted from denture base to retainers of lower distal extension removable partial dentures with conus crown telescopic system. J Oral Rehabil, 1993; 20:69-77.

39. Pezzoli M, Rossetto M, Calderale PM. Evaluation of load transmission by distal-extension removable partial dentures by using reflection photoelasticity. J Prosthet Dent, 1986; 56:329-337.

40. Laufer BZ, Gross M. Splinting osseointegrated implants and natural teeth in rehabilitation of partially edentulous patients. Part II: principles and applications. J Oral Rehabil, 1998; 25:69-80.
41. Besimo C, Graber G. A new concept of overdentures with telescope crowns on osseointegrated implants. Int J Periodontics Restorative Dent, 1994; 14:486-495.

42. Langer Y., Langer A. Tooth-supported telescopic prostheses in compromised dentitions: A clinical report. J. Prosthet. Dent., 2000; 129 -132.

43. Lee H.E., Wu J.H., Wang C.H., et al. Biomechanical analysis of distal extension removable partial dentures with different retainers. J Dent Sci, 2008; 3(3):133-139.

44. Bayer S., Komor N., Kramer A., Albrecht, D., MericskeStern, R., Enkling, N. Retention force of plastic clips on implant bars: a randomized controlled trial. Clin. Oral. Implant. Res., 2012; 23(12):1377-1384.

45. Kurtz, S.M., Devine, J.N. PEEK biomaterials in trauma, orthopedic, and spinal implants. Biomaterials, 2007; 28:4845-4869.

46. Karl M, Dickinson A, Holst S, Holst A. Biomechanical methods applied in dentistry: a comparative overview of photoelastic examinations, strain gauge measurements, finite element analysis and three-dimensional deformation analysis. Eur J Prosthodont Rest Dent, 2009; 17:5057.

47. Fernandes CP, Glantz PJ, Svensson SA, Bergmark A. Reflection photoelasticity: a new method for studies of clinical mechanics in prosthetic dentistry. Dent Mater, 2003; 19:106-117.

48. El Charkawi HG, Goodkind RJ, DeLong R, Douglas WH. The effect of the resilient-layer distal-extension partial denture on movement of the abutment teeth: a new methodology. J Prosthet Dent, 1988; 60:622630.

49. Akca K, Akkocaoglu M, Comert A, Tekdemir I, Cehreli MC. Bone strains around immediately loaded implants supporting mandibular overdentures in human cadavers. Int J Oral Maxillofac Implants, 2007; 22:101-109.

50. Majchera A., Leśniewska-Kochanekb A., MierzwińskaNastalskab E. A method and a device for the evaluation of the retention of telescopic dental crowns. J Mech Behav Biomed Mater, 2017; 69:362-367.

51. Güngör MA, Artunç C, Sonugelen M. Parameters affecting retentive force of conus crowns. Oral Rehabil, 2004; 31:271-277.

52. Akagawa Y, Seo T, Ohkawa S, et al. A new telescopic crown system using a soldered horizontal pin for removable partial dentures. J Prosthet Dent, 1993; 69:228-231. 
53. Minagi S, Natsuaki N, Nishigawa G, Sato T. New telescopic crown design for removable partial dentures. J Prosthet Dent, 1999; 81(6):684-688.

54. Asundi A, Kishen A. A strain gauge and photoelastic analysis of in-vivo strain and in-vitro stress distribution in human dental supporting structures. Arch Oral Biol, 2000; 45:543-550.

55. Sulong M. Z. and Setchell D. J. Properties of the tray adhesive of an addition-polymerization silicon to impression tray materials. J. Prosthet. Dent, 1991; 66(6):743-747.

56. Cehreli MC, Iplikcioglu H. In-vitro strain gauge analysis of axial and off-axial loading on implant supported fixed partial dentures. Implant Dent, 2002; 11:286-292

57. Stafford GD, Glantz PO. Intraoral strain gauge measurements on complete dentures: a methodological study. J Dent, 1991; 19:80-84.

58. Atwood D. A. Reduction of residual ridges: a major oral disease entity. J Prosthet Dent, 1971; 26(3):266-279.

59. DeLong R. F., Douglas W. H. Development of an artificial oral environment for the testing of dental restoratives: bi-axial force and movement control. J Dent Res, 1983; 62(1):32-36.

60. Lundgren D. F., Laurell L. Occlusal force pattern during chewing and biting in dentitions restored with fixed bridges of cross-arch extension. I. Bilateral end abutments. J Oral Rehabil, 1986; 13(1):57-71.

61. Kurtz, S. PEEK Biomaterials Handbook. Edition 1, Oxford, Elsevier Inc. 2012.

62. Carlsson G. E. Clinical morbidity and sequelae of treatment with complete dentures. J Prosthet Dent, 1998; 79(1):17-23.

63. El-Talawy D. B. Precision attachment versus extracoronal retainers on stresses transmitted to class II Kennedy partial denture cases. Masters. Cairo University, Cairo, 2003.

64. Igarashi Y. Analysis of the denture dynamics in RPD's. Part 1: methods for analyzing the denture dynamics of free-end saddle. Journal of Japan Prosthodontic Society, 1989a; 33:369 (in Japanese).

65. Igarashi Y. Analysis of the denture dynamics in RPD's. Part 2: influence of retainers on the dynamics of free-end saddle. Journal of Japan Prosthodontic Society, 1989b; 34:128 (in Japanese).
66. Ogawa M, Tohma Y, Ohgushi H, Takakura Y, Tanaka Y. Early Fixation of Cobalt-Chromium Based Alloy Surgical Implants to Bone Using a Tissue-engineering Approach. Int. J. Mol. Sci. 2012; 13(5):5528-5541.

67. Singer F., Schon F. Partial Dentures, 1st edn, 16. Quintessence Publishing Co, Chicago, IL. STEIGER, A.A. \& BOITEL, R.H. 1968.

68. Igarashi Y., Goto T. Ten-year follow-up study of conical crown-retained dentures. Int J Prosthodont, 1997; 10(2):149-155.

69. Christidou L., Osborne J., Chamberlain J.B. The effects of partial denture design on the mobility of abutment teeth. Br. Dent. J., 1973; 135(1):9-18.

70. Igarashi Y. The connecting rigidity between abutment teeth and retainers in RPD's. Journal of Japan Prosthodontic Society, 1990; 34:1162 (in Japanese).

71. Bergman B., Hugoson A., Olsson C. Caries, periodontal and prosthetic findings in patients with removable partial dentures: a ten-year longitudinal study. J Prosthet Dent , 1982; 48(5):506-14.

72. Feingold G.M., Grant A.A., Johnson W. Abutment tooth and base movement with attachment retained removable partial dentures. J Dent, 1988; 16(6):264-8.

73. Saito M., Miura Y., Notani K., Aizawa T., Matsui T., Kawasaki $\mathrm{T}$. The influence of clasp structures on load distribution of abutment teeth and ridges and displacement of denture base. The Journal of the Japan Prosthodontic Society, 1998; 42 (4):641-648.

74. Ogata K, Ishii A, Nagare I. Longitudinal study on torque transmitted from a denture base to abutment tooth of a distal extension removable partial denture with circumferential clasps. J Oral Rehabil, 1992; 19:245-252.

75. Ogata K, Watanabe N. Longitudinal study on torque transmitted from a denture base to abutment tooth of lower distal extension removable partial dentures with conus crown telescopic system. J Oral Rehabil, 1993; 20:341-348.

76. D. Wismeijer, M. A. J. van Waas, and W. Kalk. Factors to consider in selecting an occlusal concept for patients with implants in the edentulous mandible. J. Prosthet. Dent., 1995; 74(4):380-384. 